\title{
La frontera como tensión creativa: Puerto Banús, el valor de lo propio
}

\author{
Carlos HERRERA GIL \\ Arquitecto. Investigador independiente \\ cherrera@arquia2.com
}

Recibido: $15 / 03 / 2013$

Modificado: $15 / 04 / 2013$

Aceptado: $10 / 05 / 2013$

\section{Resumen}

Con el Postmodernismo en pleno y sugerente nacimiento, a finales de la década de los sesenta, se cuestiona la arquitectura existente y la herencia del Movimiento Moderno. Para la Ciudad Parque de Turismo Andalucía la Nueva, entre Marbella y San Pedro de Alcántara, arquitectos de renombre, de los más importantes del momento, intervienen con sus ideas sin éxito en cuanto a su realización. Las respuestas que podrían ser consideradas más acordes con las corrientes arquitectónicas instauradas no son contempladas. $Y$ entonces, para el diseño de uno de los elementos estrella, el puerto deportivo, la mirada de un foráneo consigue desmenuzar y extraer la esencia de lo nuestro, sobre la base de una consideración vernácula. Analizamos aquí ese reencuentro de la arquitectura popular en el cual, mediante una operación de aprehensión de conceptos e interpretación, se gesta una imagen con capacidad para perdurar y adquirir personalidad propia.

Palabras clave: Puerto Banús, regionalismo, popular, simbología, vernáculo.

Title: The Borderline as Creative Stress: Puerto Banús, the Value of its Own Abstract

With Postmodernism in full and suggestive birth, in the late sixties, the existing architecture and heritage of the Modern Movement is questioned. Renowned architects from amongst the most important at the time, get involved with their ideas for the Ciudad Parque de Turismo Andalucía la Nueva, located between Marbella and San Pedro de Alcántara, without success in their realization. The answers that could be considered more consistent with the architectural trends are discarded. And then, for the design of one of the main items, the marina, the eyes of a foreign dissect and extract the essence of our own, based on a vernacular consideration. We analyze here this reunion with popular architecture in which, by an apprehension of concepts and interpretation, an image is gestated with capacity to endure and gain its own personality.

Keywords: Puerto Banús, regionalism, popular, simbology, vernacular. 


\section{Índice}

1. El regionalismo inventado

1.1. Arquitectura popular reencontrada

1.1.1. Desde la tradición

1.1.2. Desde la modernidad

1.2. Simbología y mundo pop

1.2.1. La fuente inspiradora

1.2.2. Breve análisis semiótico

1.2.3. El artificio y la comunicación

2. Conclusión

\section{El regionalismo inventado}

\subsection{Arquitectura popular reencontrada}

\subsubsection{Desde la tradición}

Cuando comienza a gestarse el Puerto, no lo hace como un elemento aislado sino dentro de un contexto, el de un centro de turismo con elevadas aspiraciones. Sin embargo, con las primeras edificaciones, y sin ninguna intención implícita, se sientan las bases de una imagen que transciende y se revaloriza con el paso de los años. Son los bloques del Abecedario, ubicados en el muelle de Ribera y de Benabolá, los cuales, distribuidos frente a los atraques en forma de ele, cierran y conforman el perfil de la dársena principal. El arquitecto Noldi Schreck transmite sus ideas e inquietudes a José Banús y éstas adoptan la morfología de la propuesta que hoy podemos contemplar. Nos hallamos ante una arquitectura blanca, de líneas rectas, cubiertas de teja árabe y huecos de tamaño variable, jugando en planos de profundidad, mediante un arco rebajado o un simple dintel recto. La escena nos transporta poderosamente hacia un espíritu regionalista de construcciones bañadas en una deslumbrante luz, de aristas dibujadas con exhaustivo e indiscriminado rigor contra el pasivo azul celeste. Dicho espíritu parece heredado de otro tiempo, lejano en su secuencia pero cercano en nuestro interior, en un lugar donde reside un inconsciente colectivo dueño de un sentir popular.

La terminología puede variar, Fernando García Mercadal las llama arquitecturas regionales españolas (García Mercadal 1984: 13); otros autores las incluyen como arquitectura popular española (Feduchi 1978) o arquitectura vernácula. Las señas de identidad son muy concretas aunque variadas en función de la ubicación geográfica, consecuencia clara de los diferentes climas, paisajes y culturas en la propia península. En el caso de los pueblos blancos del sur, sus características están condicionadas por la elevada luminosidad de sus tierras, distinguiendo Mercadal entre dos tipos de Andalucía:

una alta, montañosa, abrupta y quebrada, en la que la piedra se encuentra por todas partes, y es utilizada para la mampostería, material de construcción aquí fácil, sólido y económico. El clima es 
templado, pero con fuertes contrastes, con grandes diferencias de temperaturas. (García Mercadal 1984: 124)

\section{y otra Andalucía,}

la baja, es llana, situada a poca altura, sobre el nivel del mar, con clima muy suave, formada con tierras de aluvión y sedimentación, en la que sus viviendas humildes, es decir populares, se construyen a base de arcilla. (García Mercadal 1984: 124)

También añade cómo estos dos tipos se entremezclan de tal modo que sus provincias participan de ambas. Divide en dos categorías, las construcciones en campo abierto y las casas rurales en los pueblos, subdividiendo a su vez la primera clase en tres, el cortijo, la cortijada y la casería. Por otra parte, Luis M. Feduchi, aunque menciona la división entre alta y baja Andalucía, prefiere centrarse en las diferencias tipológicas, conformando una lista que incluye los chozos, las cuevas, las casas de sierra y de campiña, los patios, las casas con terrado y, finalmente, los cortijos (Feduchi 1978: 9).

Una serie de elementos comunes visten a las construcciones populares, contando entre ellos, por supuesto, un origen generalmente humilde de sus pobladores, transmitiendo a su vez este carácter a sus viviendas. Mercadal nos dice que "Las casas, sus distribuciones, sus plantas, acusan su funcionalismo, dentro del género de vida de sus habitantes; casas, por fortuna, sin arquitectos" (García Mercadal 1984: 124). Este funcionalismo, no cabe duda, surge de una necesaria eficacia basada en una solución simple y directa, no por ello menos interesante. Carlos Flores, por su parte, apunta una gran cantidad de características intrínsecas relacionadas con la arquitectura popular. De ellas, entresacamos el enraizamiento en la tierra y el pueblo, el predominio del sentido utilitario, que está fuertemente ligado a la tradición de la zona y que es la arquitectura del sentido común. Añade que

en lo que concierne a los aspectos semióticos o visuales, la arquitectura popular deriva de un planteamiento generalmente desprovisto de todo prejuicio acerca de los efectos plásticos, lo que no supone en cada caso una despreocupación absoluta al respecto. (Flores 1978: 26)

Los edificios del Puerto beben de la tradición de la zona, puesto que extraen su composición y detalles de un pueblo de montaña en las cercanías. Pero, en contrapartida, sí que se preocupan de los efectos plásticos y el resultado final busca a sabiendas una imagen concreta, la plasmación surgida de lo auténtico jugando a imitar, el estado del no ser por reducción de lo existencial. 
Pero si hay una pauta básica en la arquitectura popular es sin duda su definición como conjunto. El pueblo es un todo, formado por multiplicidad de casas, y cada una es diferente a la anterior pero a la vez retiene el poso cultural creador que las hace valedoras del matiz de unidad. Carlos Flores comenta que:

mientras los hipotéticos valores de una arquitectura culta pretenden hacerse presentes hoy mediante la más acusada diferenciación entre cada obra respecto de las que le rodean, los de la arquitectura popular parecen buscar su apoyo en el conjunto, hallando su máxima valoración en esta integración de cada obra con las inmediatas [...]. Por otro lado, la arquitectura popular no repite sus obras. La diversidad -la ausencia de moldes rígidos- es una de las causas principales de su vital apariencia. (Flores 1978: 64)

Los bloques del Puerto responden perfectamente a la noción de conjunto y diversidad. Cierto es que su discurso se aparta de estas aseveraciones pero es igualmente cierto que se trata de una experiencia novedosa, investigadora a su modo de una presentación nada al uso. Aunque hay más irregularidad y caos en un asentamiento popular, la vital apariencia mencionada se deja entrever en la tectónica propia del Puerto.

Toda noción de conjunto lleva aparejado el concepto de asentamiento. En el caso de la arquitectura popular, es principalmente caótico, sin ningún plan preconcebido, lo cual contribuye a la sensación de algo orgánico que crece a su libre albedrío. Las construcciones del Puerto, por otra parte, siguen ciertas reglas de planificación como puede ser la ubicación en un frente común. Encontramos su azar más bien en la configuración de los distintos elementos en altura, en los tamaños de huecos, en las cubiertas de orientaciones variadas o en los planos de fachada no alineados entre sí. Es un remedo válido de la senda vital de lo autóctono, y de ahí su importancia y conexión con el individuo.

En la línea de la tradición constructiva de la arquitectura popular, con su austeridad, sus fachadas blancas y sus huecos aleatorios pero con un alto grado de planificación, encontramos las realizaciones del Instituto Nacional de Colonización. Una de las figuras más destacadas es Alejandro de la Sota y en él se da el "conflicto entre la idea de pueblo como resultado de un proceso orgánico de nacimiento y crecimiento natural, y la necesidad de proyectar de cero, todo un organismo complejo y contradictorio en sí mismo" (Guerra Sarabia y Pinto Puerto 2008: 381) mostrando así el casi irresoluble e inaplicable concepto de arquitectura del azar, del reflejo de la tradición y la construcción a través de los años resumidos en un acto de la voluntad humana. 
No sólo de los pueblos de la sierra se hereda esta imagen sino también del humilde pueblo de pescadores, entendido como metáfora de la arquitectura de lo blanco, de casas pequeñas encaladas mil veces, de muros gruesos perezosamente bostezando sus huecos para dejar entrar el rayo de esa luz tan generosa y abundante en el sur. Podemos pensar que el reflejo de lo sencillo, el fondo y esencia de esta arquitectura, atrae subliminalmente tanto al profesional como a la persona a pie de calle que pasea por los recodos y caminos del Puerto. Es este un punto fundamental, lo que subyace como transmisor del poder real del objeto, y cabe destacar que en el Puerto hay varios niveles de comprensión desde el puramente arquitectónico hasta el simbólicamente imbuido. Dichos niveles, por razones obvias, no son adquiridos en el momento por un observador imparcial; sin embargo, de alguna manera penetran en el subconsciente ya sea por un recuerdo casi olvidado o por la fuerza de la continuidad en el envío del mensaje (el Puerto como lugar heredado de unas costumbres y formas constructivas autóctonas). Venturi nos dice que "una arquitectura válida evoca muchos niveles de significados y se centra en muchos puntos: su espacio y sus elementos se leen y funcionan de varias maneras a la vez" (Venturi 2006: 26). El reclamo del objeto ya no es, como en los anuncios de la época "...apartamentos, casitas andaluzas...", sino la vivienda del poblado marinero reconvertida y transformada en el apartamento de lujo, una transfiguración tanto psicológica como física.

Más allá del elemento puntual, ocurre en ocasiones que una intención queda oculta e incluso puede dar lugar a interpretaciones de carácter más o menos especulativo, donde el significado de esta arquitectura junto con sus objetivos se camuflan y su resultado final no sea el originalmente proyectado. Si nos situamos en la dársena mirando hacia el norte, podemos fácilmente observar cómo las construcciones más cercanas a nuestra hipotética ubicación y la esquina de entrada al Puerto, concretamente "'Pueblo Rivera' Zona A" y "Segunda fila de Rivera", tienen una altura considerablemente más baja respecto a sus inmediatas posteriores. Nos cuenta Marcos Sainz, estrecho colaborador de Noldi en los comienzos del Puerto, que el planteamiento inicial consiste en provocar un gradiente de altura desde la dársena hacia la carretera nacional N-340, ascendente desde el mar y descendente al llegar al asfalto, pero con la particularidad de que su zona intermedia tiene acceso para las embarcaciones, conformada como un lago interior.

Surge aquí una conexión interesante, corroborada gracias al inexorable paso del tiempo y el grado de perspectiva que aporta: las realizaciones coetáneas de similares características. Por una parte tenemos la herencia de un puerto contemporáneo como es Port Grimaud, el cual, a una escala bastante mayor, desarrolla este concepto de lago interior. Recibe el sobrenombre de la pequeña 
Venecia francesa y su diseño, visto desde el aire, nos sugiere un crecimiento espontáneo debido a su trazado orgánico y de una geometría casi fractal. Su fundador es François Spoerry, que desde los seis años ya admiraba las maquetas de ciudades lacustres expuestas en museos de Zurich. Cuando alcanza la edad adulta, lleva consigo el sueño de una casa al borde del agua y de un barco en su puerta. Obtiene el título de arquitecto en 1948 y se rodea de colaboradores que, como él, sienten pasión por las casas tradicionales y la arquitectura antigua, y se opone a las realizaciones de Le Corbusier con palabras duras, decantándose más por lo que él llama la "arquitectura dulce", la cual respeta los patrimonios locales. Port Grimaud, como tal, comienza a funcionar en julio de 1967, sólo unos años antes que Puerto Banús, pero con el hecho en común con éste último de desarrollar una personalidad propia.

Por otra parte, en nuestro propio país, en el golfo de Rosas, rodeada por el Parque Natural de las Marismas del Ampurdán y entre los municipios de Rosas y San Pedro Pescador se encuentra Ampuriabrava, una marina residencial con $23 \mathrm{~km}$. de canales navegables que permiten llegar hasta la puerta de la vivienda en barco. Su andadura comienza en 1964, cuando el Ayuntamiento de Castelló d'Empuries recibe la primera documentación sobre el proyecto, aunque ésta no estaba basada en una marina. La iniciativa surge de tres figuras: el marqués de Sant Mori y los empresarios Miquel Arpa i Batlle y Vilallonga i Rossel. No es hasta 1967 cuando se obtiene el permiso definitivo para urbanizar una amplia zona entre el río Muga y Les Salins, y se comienzan a ejecutar los primeros canales de la intervención, la cual ocupará unas quinientas hectáreas una vez terminada.

Como puede verse, hay una gran similitud entre las dos intervenciones, al nivel conceptual del uso del agua como elemento de comunicación y de distribución interior. La morfología resultante, sin embargo, es diferente. Ampuriabrava aparece más estratificada y regularizada mientras que Port Grimaud es más orgánico e irregular. Ambas son éxitos turísticos en sus respectivos ámbitos. Como todos ya sabemos, ningún canal ni zona lacustre se ejecuta finalmente en el Puerto Banús. Esta circunstancia no merma ni la calidad de lo obtenido ni su repercusión a nivel internacional.

Así pues, en nuestro caso encontramos cómo la tradición revestida de experimentación nos regala un Pueblo Marinero desde una arquitectura popular mediterránea. Su sugerencia de austeridad alberga, en oposición, un mundo interior de riqueza, lujo y ostentación. El pueblo portuario presenta unidad en su ejecución, aportándole esta característica cualidades de conjunto. Esto ayuda, a su vez, a interpretar todos los bloques como una intervención única en lugar de individualizarlos. Al igual que ocurre en los asentamientos 
vernáculos, las construcciones del Puerto se apoyan unas en las contiguas para contener esa imagen inequívoca de poblado rústico.

\subsubsection{Desde la modernidad}

No es fina la línea que separa lo popular y vernáculo de lo racionalista. Sin embargo, Banús tiene la opción dos veces, como mínimo, de decantarse hacia sendas propuestas de un lenguaje arquitectónico organizado, funcional y lineal. Estamos en la década de los sesenta y el postmodernismo está asomando en el horizonte. La crisis del Movimiento Moderno es ya patente, Aldo Van Eyck habla del vacío cultural dejado por la pérdida de lo vernáculo en el IX CIAM, donde se produce el cisma con los maestros establecidos. Deja clara la idea de identidad, la "pertenencia como una necesidad emocional básica" y la idea del lugar.

En este contexto, el empresario recibe la propuesta de Antonio Bonet para el Grupo Hotelero de Playas. Tiene una magnitud y una envergadura dignas de su posible ubicación y destino, con un gran proyecto central de líneas infinitas y geometrías regulares. Posteriormente, hacia el final de la década, recibe de Antonio Lamela un diseño para el poblado marinero de corte casi futurista con sus escaleras de acceso circulares y sus terrazas apaisadas. La realidad final es bien distinta, como ya sabemos. El rechazo es llamativo pues ambos son trabajos de un elevado interés y son ideas descartadas por algo tan diferente como lo que finalmente se construye. Se puede leer con certeza la crisis ideológica arquitectónica, que en poco tiempo se va a sumar a la económica, marcando el final de las grandes intervenciones hoteleras. En esta tesitura, lo vernáculo y popular viene como una fresca brisa a renovar el panorama establecido. En nuestro caso no lo hace con la simplicidad intrínseca de las viviendas de pueblo, sino como algo más.

Con las segundas líneas de edificación se estira la tipología, ganando en altura, bien por un afán de rentabilidad económica, bien por un criterio de diseño como ya comentamos, o incluso por una mezcolanza de intenciones. Aquí, la reinterpretación alcanza su apogeo y la elevación separa la conceptualidad de la intención primera del fingimiento veraz de las posteriores, ganando en el camino la enriquecida lectura del conjunto. No solo obtiene la iconografía y teatralidad derivada de su frente-escenario tal y como se ve desde el dique de Levante sino que, por añadidura, recrea un espacio de interés, a la vez trasera y portada, el cual no es otro que la calle interior, donde conviven las cocinas y servicios de restaurantes con las entradas escalonadas a las distribuciones de los portales de las viviendas y apartamentos. Su angosta latitud y los bloques que la conforman pueden disfrazar lo observado y hacer creer que se pasea por una calle de una población, en lugar de por un puerto deportivo. Pero las estratégicas permeabilidades hacia el sur 
disipan cualquier rastro y confirman, con los mástiles de las embarcaciones y el mar en calma, la ubicación exacta donde nos encontramos. Esta calle dibuja una suerte de patio de manzana con aperturas en los extremos y conexiones intermedias, un volumen abierto (Venturi 2006: 131) sin llegar a ser completamente residual. Caracterizarlo así es, en nuestra opinión, por la fuerza e importancia de los espacios exteriores, con los cuales mantiene una relación topológica y una tensión constitutiva. Además, en una lectura transversal del Puerto, la calle interior y su volumen desempeñan la función de ser una articulación entre la dársena y la calle del muelle de Ribera, ejecutando una transición casi continua pero mostrando cada uno de los espacios con su propia idiosincrasia formalizadora.

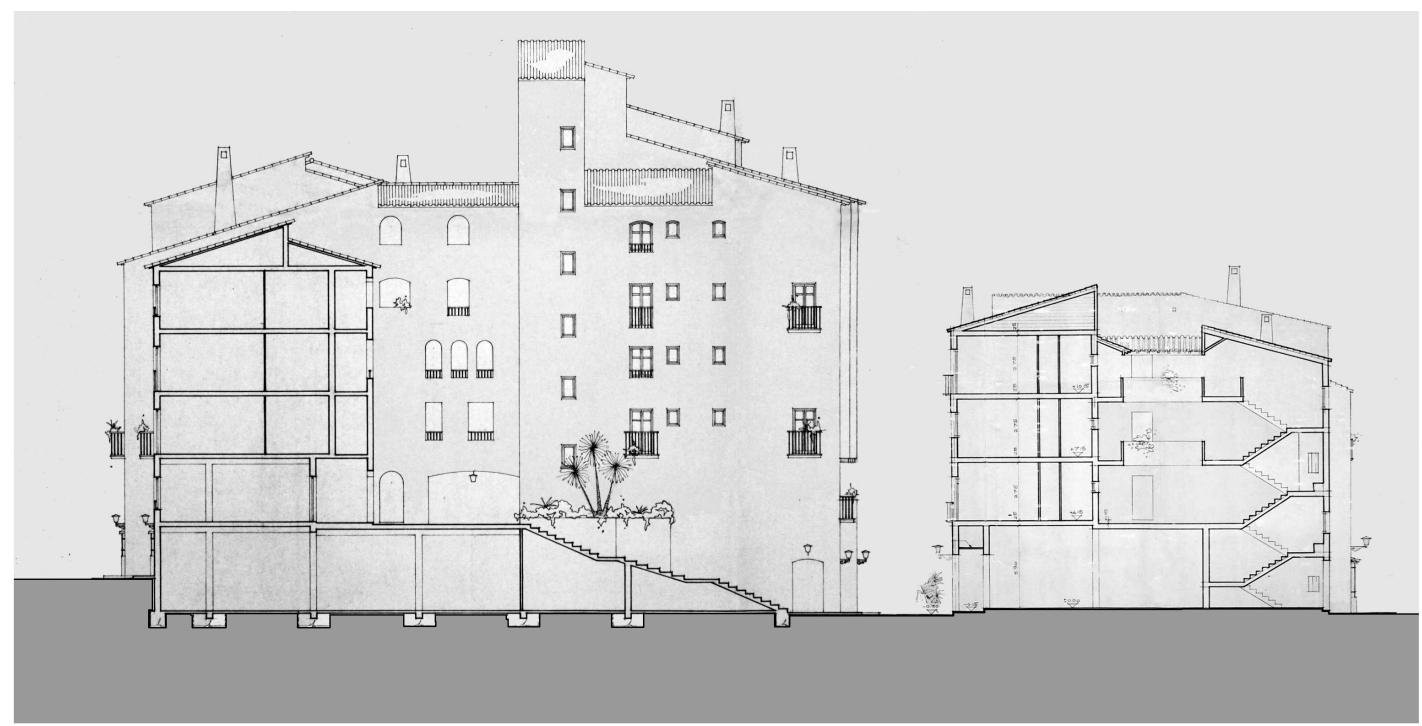

Figura 1. Sección transversal por las Casas Y y M. Se aprecia la calle interior.

Sin llegar a ser un fenómeno de inflexión, ya que el conjunto se manifiesta por la naturaleza de las partes (Venturi 2006: 144) además de por su posición y número, las segundas líneas de edificación $y$, en general, los bloques altos del Puerto son el paradigma y el más alto grado de significación del fenómeno reinterpretativo. Es aquí donde la realidad desdibujada se torna diferente y se aleja de su objeto-fuente. No quiere decir esto que en los demás edificios no se dé esta coyuntura, pues de hecho se da, la cual ya por sí misma implica un desarrollo del proceso lecturaasimilación-idea-desarrollo-proyecto para obtener un objeto nuevo. Se podría decir que el grado es proporcional a la altura empleada, diferenciándose en su idealización de la tipología extendida y más común de vivienda popular, del arquetipo de lo vernáculo. Como en la operación pop, el artista "ha demostrado el valor del viejo cliché que se emplea en un nuevo contexto para conseguir un significado nuevo -la lata de sopa en la galería de arte- para hacer insólito lo común" 
(Venturi 2004: 97). Vittorio Gregotti identifica el proceso pop con la dimensión de la inutilidad, aportando un punto de vista que difiere del anterior. Afirma que:

el desplazamiento se obtiene a través del cambio del material, a través del uso del material impropio, con el camuflaje de la función o el contraste indebido entre su forma que se presenta siempre como forma de alguna otra cosa muy reconocible, y la forma misma. (Gregotti 1973: 258)

Nos situamos más en la primera noción, la que asevera que se produce un significado nuevo haciendo insólito lo común. El trabajo invertido en provocar el desplazamiento, pues estamos de acuerdo en que esto sí existe, produce un original a partir de lo auténtico. La particularidad es que dicho original produce contraste en su separación del contexto primigenio y realza su estatus en presencia de unas condiciones de contorno alejadas de su hábitat natural. Además, la autenticidad del objeto inspirador está revestida de la tradición constructiva local y popular, con su porcentaje de objeto común en entornos concretos, como puede ser el caso de un pueblo de serranía.

\subsection{Simbología y mundo pop}

\subsubsection{La fuente inspiradora}

Queda una visión especial, la cual creemos encierra la riqueza, la versatilidad y el potencial más concreto del objeto de análisis, protagonista indiscutible y culpable de ser un fenómeno turístico. Antes de pertenecer a la masa, e incluso después, es dependiente del mundo de las ideas y de la mente, es decir, el símbolo subyace en el referente real físico (las edificaciones del Puerto) y dicho vínculo es con su referente construido, con el cual contrae una deuda estética. Hablamos del pueblo costero de Casares, que se muestra como un ejemplo especial entre este tipo de asentamientos gracias a su topografía tan inclinada. Está situado en la comarca conocida como Costa del Sol Occidental, a unos 22 kilómetros de Estepona, sobre los últimos pliegues de la serranía de Ronda. De calles con empinadas cuestas, su imagen de casas blancas y cubiertas de teja árabe sirve de base y fundamento a la intervención inicial del Puerto. Carlos Flores lo menciona de manera especial y le llaman la atención las

soluciones de viviendas muy particulares, entre las que destacan las constituidas por edificios de tres o cuatro plantas con acceso a las dos primeras por una calle y a las tercera y cuarta por otra más o menos paralela a la anterior, pero situada a una cota cuatro o cinco metros más alta. (Flores 1978: 153) 
El arquitecto Noldi Schreck y su equipo extraen de sus construcciones toda clase de datos, no solo tipológicos, llegando a tomar incluso las medidas de los huecos en las fachadas para hacer una recopilación estadística. La intención es poder extrapolarla y usarla en la primera presentación realizada a José Banús, con un diseño preliminar de la línea estética escogida. Junto a Noldi Schreck trabaja Marcos Sainz, persona de confianza y amigo suyo desde antes de la Universidad. Por aquella época, ambos se dedicaban a la arquitectura del turismo en Méjico, antes de que Alfonso de Hohenlohe traiga al primero a España. La propuesta inicial conlleva un trabajo muy intenso con fotografías, mediciones, elaboración de base de datos, y el resultado final, nos comenta Marcos Sainz, le choca a José Banús, quien no quiere entender el cambio que se está realizando desde las intervenciones lineales y modernas de Antonio Bonet Castellana o Antonio Lamela hacia el pueblo mediterráneo y vernáculo de Noldi Schreck. Como es conocido, la influencia de la aristocracia local es fuerte y sabemos el final de la historia y que Puerto Banús se ejecutó. Sobre todo este momento, además de las no pocas influencias y decisiones de las personalidades locales, planea la crisis teórica de la arquitectura racionalista. En la introducción a su libro, Fernando Tudela ya nos anticipa esta situación y cómo es importante su referencia para elaborar "el desarrollo de un enfoque semiótico de la arquitectura" (Tudela 1975: 11). En el diseño del Puerto es especialmente significativo el abandono de la modernidad por lo rústico y popular. Tiene más lecturas debido al hecho de ser, por otra parte, la imagen a la que el régimen dictatorial da su beneplácito y escoge para ser exportada al exterior: el símbolo es interno, perteneciente a la cultura del pueblo; la imagen es local y arraigada además de pintoresca y sugerente. La forja de un Imperio ha quedado atrás pero el casticismo se hace más presente y revalorizado.

Con estas premisas, el planteamiento simbólico es una parte obvia del camino analítico a seguir. Apoyamos este enfoque semiótico de la lectura de las construcciones del Puerto, el cual arroja una visión más completa pues tiene en cuenta no sólo el elemento significante como transmisor de un mensaje, sino al factor social y humano como receptor y decodificador de dicho mensaje. En este punto, usamos como herramienta la semiología estructuralista europea (Eco 1994: 9), heredera de las bases sentadas por Ferdinand de Saussure, suficientemente extendida y consolidada. 


\subsubsection{Breve análisis semiótico}

Saussure, en su libro Curso de lingüística general, establece las definiciones de significante/significado y la relación existente entre cada elemento como tal y en oposición al resto, lo que proporciona ese carácter de estructura al sistema lingüístico. Umberto Eco se sustenta en esta dicotomía y presenta en La estructura ausente un enfoque semiótico a la arquitectura elaborando un discurso sobre la función y el signo (Eco 1994: 279-339). Deja claro que "la arquitectura puede ser considerada como un sistema de signos" (Eco 1994: 285) y también su indiscutible carácter comunicativo. Hace hincapié en como los objetos "comunican incluso sin ser usados" (Eco 1994: 282) y es la función la que se encarga de este papel, siempre inmersa en una sociedad que lo contextualiza y adecua. Coincidimos con Eco en este criterio y es un sólido punto de partida admitir que el Puerto comunica, si bien pensamos que en este caso hay una doble funcionalidad, adquirida intencionadamente desde su concepción como obra arquitectónica y aumentada con la perspectiva histórica.

Eco distingue entre funciones primarias, las que se denotan, y funciones secundarias, las que son connotadas. Además, dice que

no tienen valor discriminativo en sentido axiológico (como si una fuera más importante que la otra), sino de pura mecánica semiótica, en el sentido de que las funciones secundarias se apoyan en la denotación primaria... (Eco 1994: 296)

En nuestro objeto de estudio, entendemos para el conjunto edificado una funcionalidad interna, derivada de los apartamentos y locales como uso arquitectónico (lo cual nos daría su función primaria) además de añadir a dichos apartamentos y locales el hecho connotado del lujo, de la exclusividad otorgada a la construcción (función interna secundaria); y una funcionalidad externa portadora de una fuerte carga simbólica connotativa como contenedores y delimitadores de la dársena (lo cual nos da una función secundaria).

Todas estas funciones descritas son los significados atribuidos al hecho físico, ya sea en un plano denotativo o en uno simbólico. En cualquiera de los casos, el sustrato compositivo no es otro que la transmutación, la cautelosa y estudiada transliteración de un código previo, cuyos elementos integrantes pueden ser entendidos como semánticos en tanto que se corresponden con una articulación de elementos arquitectónicos y de géneros tipológicos. Eco argumenta, en primera instancia, que este tipo de codificación formaliza soluciones ya elaboradas $y$, de este modo

si los códigos arquitectónicos no me permiten traspasar ese límite, en este caso la arquitectura no es una manera de cambiar el curso de la 
historia y de la sociedad, sino un sistema de reglas para dar a la sociedad lo que ésta prescribe a la arquitectura. (Eco 1994: 312)

Y así la caracteriza de servicio para satisfacer una demanda previamente constituida. Nosotros pensamos que en nuestro caso sí se produce una rica lectura con significado de una forma de construir popular llevada a un nuevo contexto, con un elevado grado de acierto. Renato de Fusco presenta al Movimiento Moderno con una gran crisis en su lenguaje y dice:

[...] tanto en el aspecto representativo como en el comunicativo de la arquitectura, [...] precisamente en un momento en que aquella quizás presenta la mayor carencia semántica de su historia. (De Fusco 1970: 147)

Resaltamos este concepto porque en la concepción del Puerto se abandona específicamente una tendencia racionalista, de líneas preferentemente rectas y volúmenes definidos en favor de un diseño más autóctono, desordenado dentro de un esquema y con volúmenes cambiantes desarrollados en planos de profundidad variable; es decir, se cambia un código de supuesta modernidad por otro que, a la postre, abarca más significados.

Figura 2. Alzado principal de la calle interior, desde la Casa O hasta la Z.

Sirvan como ejemplo de este aspecto del Puerto, las construcciones del muelle de Ribera. Destinadas a provocar el gradiente de altura, no se completan al norte y no se conforma ningún acceso interno al mar sino, todo lo contrario, se dejan en un comienzo dichos edificios aislados e inintencionadamente se produce una fachada que mira hacia la carretera nacional N-340 San Pedro de Alcántara-Marbella con unas marcadas características de trasera debido a su altura, el número de huecos y ventanas y su distribución. Este resultado no buscado altera las lecturas y el entendimiento, creando y reforzando la noción de telón que sirve a la vez de ocultación de la parte posterior pero también de invitación a traspasar la frontera y acceder al verdadero Puerto que se esconde detrás. Venturi nos dice que:

Mientras la segunda clasificación de complejidad y contradicción en arquitectura se refiere a la forma y contenido en cuanto son expresiones del programa y estructura, la primera trata del medio y se refiere a una paradoja intrínseca a la percepción y al proceso de significación en el arte: la complejidad y la 
contradicción como resultado de la yuxtaposición de lo que una imagen es y lo que parece. (Venturi 2006: 33)

Es, en nuestro caso, una fachada interior, al menos en origen, pero asemeja una fachada trasera. Añade además que

Si la fuente del fenómeno de lo uno y lo otro es la contradicción, su base es la jerarquía, que admite varios niveles de significado entre elementos de valores diferentes [...]. Una arquitectura que incluye diversos niveles de significado crea ambigüedad y tensión. (Venturi 2006: 39)

Nuestra ambigüedad surge del proceso creativo interrumpido, de la proyección no formalizada $y$, por tanto, de la falta de continuidad y del desorden provocado. No obstante, de la realidad ejecutada se configura una tipología, la cual más tarde desemboca en la calificación que el Plan General de la ciudad de 1986 adopta como Pueblo mediterráneo, definido mediante juegos de volúmenes, escalonamientos y repartos de edificabilidades según plantas muy característicos y singulares.

En arquitectura, la definición semiótica de código es más compleja que, por ejemplo, en el lenguaje, donde Martinet, en 1960, establece la definición de doble articulación para indicar sendos niveles de estudio. Una primera articulación se compone de elementos dotados de significado (monemas, combinados unos con otros para formar sintagmas), y una segunda articulación es el producto de la descomposición de los elementos iniciales (división en fonemas) en otros más simples, carentes de significación por sí solos, obteniéndola por medio del juego mutuo entre ambos. Cuando Umberto Eco intenta definir el código arquitectónico comenta que:

Cuando hemos pasado a tratar de los códigos visuales nos hemos visto obligados a enumerar una serie de distintos niveles de codificación, desde el código icónico al código iconológico; y para ello nos hemos visto obligados a hacer una serie de precisiones sobre el concepto de código y sobre los distintos tipos de articulación que el código prevé. (Eco 1994: 308)

Tanto De Fusco como Eco, como estructuralistas, parten de la premisa de la existencia de una articulación. Estamos de acuerdo con ellos pero también con la idea de que, en el caso de la arquitectura, dicha articulación es diferente a la expuesta anteriormente, no necesariamente ha de ser de tipo doble, pudiendo abarcar más campos de complejidad. En este sentido, Gillo Dorfles sostiene la opinión de 
que es imposible proponer una partición del "signo" arquitectónico en pequeñas partículas (equiparables a los fonemas y morfemas del lenguaje verbal). De este hecho nace la inutilidad de hipotetizar sobre una "doble articulación" en el lenguaje arquitectónico como ha propuesto Martinet para el lenguaje hablado o escrito. (Dorfles 1980: 166)

Plantea, como más probable, la hipótesis de una articulación morfológica y una sintagmática. El análisis de esta temática merece un estudio más exhaustivo en un documento aparte, con toda seguridad. Lo que sí consideramos cierto es que la adopción y adaptación del código arquitectónico de una arquitectura popular andaluza como la de Casares (entre otros pueblos) integra, en este caso concreto intencionadamente, las articulaciones sustanciales de los elementos constituyentes, desde las formas de los huecos en los paramentos y sus relaciones dimensionales y de ubicación hasta el uso de los materiales o su relación compositiva.

\subsubsection{El artificio y la comunicación}

En lo que todos estos autores mencionados están de acuerdo, en mayor o menor medida, es en que la arquitectura comunica. De Fusco llega a proponerla como "medio de masas" en un intento de asociar la cultura de masas con la semiología, como comenta Oriol Bohigas. Puerto Banús responde a los tiempos modernos en los cuales surge negando su vinculación con el reciente poso cultural de las tendencias arquitectónicas a la vez que asomándose a una estética popular y consolidada, amparada en su antigüedad y más que demostrada funcionalidad. Su imagen pertenece al pueblo y su conexión y comunicación se establece en este sentido. En una interpretación de largo recorrido, en el comienzo está la casa de pueblo mediterránea, de escasos recursos, superficie reducida si está en el núcleo urbano, evolucionando con el paso de los años y con las distintas ubicaciones peninsulares hasta llegar a la descontextualización intencionada de un diseño artificioso, en tanto que reensamblado de una población específica. La esencia del origen se transfiere y permanece latente en la visión cotidiana de las edificaciones portuarias. No nos cabe duda de que este ingrediente forma parte de la durabilidad y el acierto presentes en las Casas de Banús. La constante tipológica subyacente mantiene el espíritu inicial y es el justo y necesario vínculo con el hombre corriente y su entorno cercano. De este modo, la simbología se pone al servicio de la creación del pueblo de montaña en el borde del mar, el cual, por añadidura, es artificial.

En una frase muy acertada y adecuada, Venturi dice: 
La riqueza puede proceder de la arquitectura convencional. [...] Pero también puede llegar a través de un reajuste de la escala o el contexto de los elementos convencionales y habituales para obtener significados insólitos. Los artistas Pop empleaban yuxtaposiciones insólitas de objetos cotidianos en un juego tenso y vivo entre asociaciones viejas y nuevas para mofarse de la interdependencia cotidiana entre contexto y significado, con lo que nos daban una interpretación nueva de los artefactos culturales del siglo XX. Lo familiar que esta un poco off tiene un poder extraño y revelador. (Venturi 2004: 162)

Eco coincide con Venturi en cuanto a la "descontextualización del signo y su inserción en un nuevo contexto que lo llena de significados nuevos" (Eco 1994: 303), mencionando asimismo su carácter de operación pop. En nuestro caso, el reajuste de escala y contexto es fundamento y base de la realización del Puerto. Resulta evidente su ubicación fuera de contexto como concepto formal de partida. Por otra parte, las propias edificaciones deforman la percepción de lo extraño para introducirlo en el campo de lo cotidiano. Con el paso del tiempo se produce una transformación del objeto simbólico en referente para otros objetos posteriores, aunque para el ojo experto no se pierde la conexión con su origen.

José Banús siempre promociona, como ya vimos, sus inversiones inmobiliarias pero, en el caso del Puerto, vuelca sus recursos en la promoción a nivel nacional e internacional. Nace pues como símbolo fisonómico de significados arquitectónicos y, a la vez, crece como símbolo de un mundo lujoso poco accesible. Con el devenir del tiempo, los locales comerciales van llenándose de tiendas y negocios con sus marcas específicas, iconos de cada época, reconocibles por la mayoría de las personas, los cuales son una expresión directa de un proceso comunicativo. El mundo pop del diseño alcanza principalmente al turista y los logotipos de marcas conocidas conquistan el caminar zigzagueante a través de su asfalto o de sus aceras. El icono se convierte en contenedor de iconos, reafirmando y retroalimentando su imagen en el proceso. En cierto sentido, se dan múltiples ejemplos de la heráldica venturiana con enormes carteles de tipografía destacada, apoyándose y contrastando con la arquitectura popular proyectada (Venturi 2004: 129), la cual, siguiendo la línea argumental de Venturi, es un pato, si bien nosotros lo entendemos más como un pato a posteriori, es decir, la forma simbólica global ganada a medida que crecen las construcciones y, como dijimos en el párrafo anterior, reconvertida finalmente en referente. Este significado obtenido a partir de los elementos de una arquitectura vernácula, reensamblados en algo nuevo, es el valor de lo inventado. La pregunta consiguiente es: ¿llega por igual a todo el mundo? O lo que es lo mismo, ¿comunica por igual a cualquier 
visitante? Es casi obvio que no resulta igual el Puerto a un visitante malagueño que a un gallego o, en un extremo más radical, que a un japonés. Eco dice que "seleccionamos los aspectos fundamentales de lo percibido basándonos en códigos de reconocimiento". Dichos códigos van a remarcarnos los elementos que consideramos pertinentes del objeto visualizado, los cuales pueden variar en función de la cultura de procedencia. También concluye que "la reconocibilidad del signo icónico depende de estos aspectos" (Eco 1994: 195). Es posible pensar que la contemplación de los edificios portuarios no lleve al individuo a la conclusión de que está frente a la reducción conceptual de una arquitectura local, y por extensión, al arquetipo de la arquitectura popular. Sin embargo, de uno u otro modo, quien entra en contacto con las Casas del Puerto tiene en un cierto grado un poso de conocimientos que le van a servir de código para poder interpretarlas. La comunicación está garantizada pero, como señala Dorfles, admitiendo la posibilidad de

una "semanticidad tipológica" de determinadas expresiones arquitectónicas según el significado simbólico-comunicativo que ellas revisten dentro de los límites y de los caracteres de una determinada época cultural. (Dorfles 1980: 190)

En nuestro caso, frente al Movimiento Moderno con su seriación y falta de significado según De Fusco, el reencuentro con una arquitectura autóctona de bordes imprecisos y composición orgánica, además respuesta de una cultura integrada por muchos años en el seno de nuestra sociedad.

Tenemos pues, de un lado la comunicación a escala humana, cercana, centrada en los comercios del Puerto. Marcas y logotipos son su bandera, su estandarte. Un mundo de colores y grafismos distintivos conquista las pupilas del caminante, invitándole a participar sin demora. Y por otro lado, la comunicación a escala arquitectónica, fluyendo sin pausa desde las construcciones y los bloques del Puerto, menos directa que la anterior pero con raíces más profundas, adentrándose en las tradiciones locales, junto con los modos de vivir y sentir populares.

\section{Conclusión}

La imagen característica del Puerto se consigue en la primera mitad de la década de los setenta, en la cual ya están planteados todos los bloques del Abecedario, nombrados así pues cada conjunto responde a una letra. Adquiere progresivamente más fama, apoyada en unos comienzos acusadamente mediáticos. Alrededor del nombre de Puerto Banús se consolida una aureola de exclusividad y riqueza, llamando la atención de múltiples fortunas europeas y de fuera del continente. Con el final de la dictadura y el comienzo de otra época 
más aperturista, la idealización se apodera de la idea y el tipo de turista deja de ser tan elitista para abrirse a una masa más heterogénea. Se busca ese Pueblo Marinero que no es otra cosa sino un reflejo de otra arquitectura, la transliteración de una forma de construir, de vivir, evocando a las construcciones populares y tradicionales. El valor de lo propio está expuesto en los alzados del Puerto. No es Casares, pero sin duda lleva algo de éste. A su vez, no es un pueblo de serranía pero dispone para su deleite esta coyuntura a pie de mar. Hay una transición popular-herencia-reinterpetadonuevo detectable y perceptible, aun de modo subliminal. Los niveles de significado se han complejizado con el paso del tiempo y la denotación Puerto Banús adquiere fuertes valores connotativos.

Nadie podía pensar que el valor de lo propio residiría con tanta fuerza en un reensamblaje de un código arquitectónico vernáculo. Pero lo hace y lo mantiene vivo, en constante referencia con su ascendente proyectual. La segunda mitad de la década de los sesenta ve el final de la era de los grandes edificios turísticos y el auge de lo autóctono, aunque se trate de algo fingido o reinterpretado; y esta manera de proceder se hace presente en la materialización del Puerto, sumergiéndose de este modo en la cultura del simulacro. Es una especial forma de hacer y proyectar, es el fenómeno turístico basado en la imagen. Desde Las Vegas hasta Dubai mucho se ha avanzado, pero el procedimiento de camuflaje sigue siendo el mismo. La arquitectura es un telón con una riqueza intrínseca discutible maridada con una vocación teatral incuestionable. Nuestra sociedad está llena de alardes tecnológicos sin alma, realizados por el exclusivo honor o placer de su posibilidad convertida en certeza. En el Puerto como ejercicio compositivo se advierten valores de muy difícil repetición, tanto de diseño como de voluntades. Mediante una tecnología común en la época se alcanza una solución trascendente, ratificando la validez de avalar una idea con grandes posibilidades. Tan importante como la elección final son los descartes producidos en el camino, pues nos hablan de un momento histórico de cambio, un punto de inflexión que trae una nueva lectura de la arquitectura en la cual todos podemos participar. Dichos descartes representan el paradigma del cambio, lo único permanente en el devenir del hombre. La sociedad exterioriza sus cíclicos procesos en esfuerzos de transición y posterior transformación en algo nuevo, o revisitado pero desde un punto de vista inédito. En la no aceptación de la imposición estilística y arquitectónica del Movimiento Moderno hay un implícito rechazo a la deshumanización y a la seriación. El contenido teórico abstracto de la arquitectura de posguerra choca frontalmente con una sociedad que lleva dos décadas en busca de otros ideales diferentes y se hace cierto el hecho de que no está preparada para este tipo de respuesta cultural. Las propuestas desestimadas de Bonet o Lamela dan sobrada prueba de este comportamiento. Más aún, sumados al 
cambio cultural global, aquí nos mostramos mucho menos postmodernistas y bastante más autóctonos. En el espacio colectivo común reside la esencia de una imagen de pueblo blanco y teja, y el valor de lo propio es el valor de lo antiguo y tradicional a través de un nuevo lenguaje.

\section{Bibliografía}

ÁLVAREZ, Fernando et alii (1996): Antoni Bonet Castellana 1913-1989. Edición a cargo de Fernando Álvarez y Jordi Roig. Barcelona: Col-legi d'Arquitectes de Catalunya / Ministerio de Fomento.

DE FUSCO, Renato (1970): Arquitectura como "mass medium". Notas para una semiología arquitectónica. Barcelona: Anagrama.

DORFLES, Gillo (1980): La arquitectura moderna. Barcelona: Ariel.

ECO, Umberto (1994): La estructura ausente. Introducción a la semiótica. Barcelona: Lumen.

FEDUCHI, Luis (1978): Itinerarios de arquitectura popular española. 4 - Los pueblos blancos. Barcelona: Blume.

FLORES, Carlos (1978): Arquitectura popular española, vols. 1 y 4 . Madrid: Aguilar.

GARCÍA MERCADAL, Fernando (1984): Arquitecturas regionales españolas. Madrid: Consejería de Cultura, Deportes y Turismo de la Comunidad de Madrid.

GREGOTTI, Vitorio (1973): "Kitsch y arquitectura", en Gillo Dorfles (ed.), EI Kitsch: antología del mal gusto, pp. 251-272. Barcelona: Lumen.

GUERRA SARABIA, Inmaculada; y PINTO PUERTO, Francisco (2008): "Miradas cruzadas. Arte e ideología en la configuración del poblado de Esquivel", en Instituto Andaluz del Patrimonio Histórico (ed.), Pueblos de colonización durante el franquismo: la arquitectura en la modernización del territorio rural, pp. 372-384. Sevilla: Consejería de Cultura.

TUDELA, Fernando (1975): Hacia una semiótica de la arquitectura. Sevilla: Secretariado de Publicaciones de la Universidad de Sevilla.

VENTURI, Robert (2006): Complejidad y contradicción en la arquitectura. Primera edición: 1966. Barcelona: Gustavo Gili.

VENTURI, Robert et alii (2004): Aprendiendo de Las Vegas, el simbolismo olvidado de la forma arquitectónica. Primera edición: 1972. Barcelona: Gustavo Gili. 